\title{
Corinne Bonafoux, Matthieu Brejon de Lavergnée (dir.), Autour du fait religieux. Nouvelles recherches en histoire contemporaine
}

Paris, Beauchesne, 2013, 326 p.

Jean-Dominique Durand

(2) OpenEdition

Journals

Édition électronique

URL : http://journals.openedition.org/assr/26329

DOI : $10.4000 /$ assr.26329

ISSN : $1777-5825$

Éditeur

Éditions de l'EHESS

Édition imprimée

Date de publication : 31 décembre 2014

Pagination : 149

ISBN : 978-2-7132-2467-6

ISSN : 0335-5985

\section{Référence électronique}

Jean-Dominique Durand, « Corinne Bonafoux, Matthieu Brejon de Lavergnée (dir.), Autour du fait religieux. Nouvelles recherches en histoire contemporaine », Archives de sciences sociales des religions [En ligne], 168 | 2014, mis en ligne le 07 avril 2015, consulté le 22 septembre 2020. URL : http:// journals.openedition.org/assr/26329; DOI : https://doi.org/10.4000/assr.26329 
Corinne Bonafoux, Matthieu Brejon de Lavergnée (dir.), Autour du fait religieux. Nouvelles recherches en histoire contemporaine

Paris, Beauchesne, 2013, 326 p.

Jean-Dominique Durand

RÉFÉRENCE

Corinne Bonafoux, Matthieu Brejon de Lavergnée (dir.), Autour du fait religieux. Nouvelles recherches en histoire contemporaine, Paris, Beauchesne, 2013, 326 p. 
1 L'Association française d'Histoire religieuse contemporaine, fondée en 1974 par Jacques Gadille et Jean-Marie Mayeur, organise chaque année une journée d'études dont plusieurs ont été publiées chez des éditeurs divers. Cette fois, les responsables de l'Association ont choisi de rassembler «un florilège de communications » provenant des Journées de 2005 sur les États-Unis, de 2006 sur «Nouveaux chantiers en histoire religieuse ", de 2007 sur « Culpabilité », de 2009 sur les dialogues interreligieux et de 2010 sur «Approches religieuses du social ». Treize études sont ainsi rassemblées, réunies en quatre parties. La première est consacrée à "Une histoire sociale du religieux", introduite par Matthieu Brejon de Lavergnée, avec les

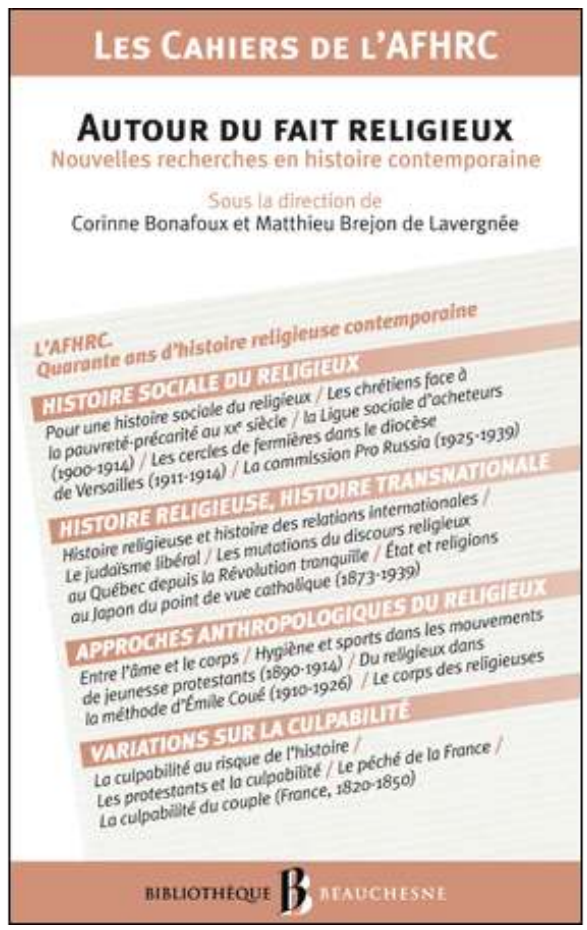
études d'Axelle Brodiez-Dolino sur la pauvreté-précarité au $\mathrm{Xx}^{\mathrm{e}}$ siècle, de MarieEmmanuelle Chessel sur la Ligue sociale d'acheteurs, de Mathilde Guilbaud sur des cercles de fermières, et de Laura Pettinaroli sur la commission vaticane Pro Russia.

La deuxième partie introduite par Florian Michel, avec pour titre « Histoire religieuse. Histoire transnationale ", réunit les contributions de Sébastien Tank-Storper sur le judaïsme libéral, de Florian Michel sur le Québec, d'olivier Sibre sur le Japon. La troisième partie s'attache à "Une approche anthropologique du religieux ", avec une présentation de Nicolas Champ et les interventions d'Arnaud Baubérot sur l'hygiène et le sport dans les mouvements de jeunesse protestants, d'Hervé Guillemain sur «Le religieux dans la méthode thérapeutique laïque d'Émile Coué », et de Sabine Rousseau sur «Le corps des religieuses entre réformes conciliaires et révolution des mœurs ». La quatrième partie propose des «Variations sur la culpabilité » introduites par Corinne Bonafoux, qui rassemblent Pierre-Yves Kirschleger pour les protestants, Jacques Marx pour « une représentation du champ politique comme champ de bataille spirituel au $\mathrm{XIX}^{\mathrm{e}}$ siècle » et Claude Langlois pour les couples aux débuts de la limitation des naissances dans les années 1820-1850.

3 L'inconvénient que présente un tel ouvrage, on le perçoit vite à travers cette rapide énumération, c'est la juxtaposition d'un grand nombre d'études, du reste toutes de grande qualité, qui est mal masquée par le regroupement en quatre thèmes. L'avantage, qui n'est pas mince, est de montrer la vitalité de l'histoire religieuse, le renouvellement des sujets et des modes d'approche, et l'émergence d'une nouvelle génération de chercheurs intelligente, dynamique, qui ouvre la voie avec un enthousiasme réconfortant à un renouvellement des thématiques classiques. C'est pourquoi l'introduction générale de Jacques-Olivier Boudon, laisse quelque peu perplexe pour le pessimisme qu'il exprime quant à l'avenir de l'histoire religieuse notamment dans les universités françaises. Il est vrai qu'après une longue phase d'expansion, on observe un repli en termes de postes. Il faudrait à ce sujet s'interroger sur le comportement 
suicidaire de certains collègues qui, pour des calculs médiocres, acceptent de masquer l'histoire religieuse dans des entités où celle-ci est noyée, et même n'existe plus vraiment, et sur les raisons réelles de la suppression de postes de Professeurs en histoire religieuse : l'anticléricalisme a ici bon dos. Plus préoccupant est le désintérêt des institutions religieuses pour leur propre histoire, et plus généralement pour les sciences humaines. Le clergé érudit passionné par l'histoire, la sociologie, voire l'ethnologie, est vieillissant et disparaît peu à peu. La nouvelle génération d'évêques et le jeune clergé - pour l'Église catholique, mais est-ce différent pour les autres confessions ? - n'accordent que peu d'importance à la recherche universitaire dans ces disciplines. Mais est-ce un obstacle lorsque l'intérêt du public, mais aussi des pouvoirs publics, ne faiblit pas?

4 On peut compter sur le dynamisme des jeunes chercheurs réunis dans cet ouvrage et de bien d'autres qui font vivre l'Association française d'Histoire religieuse contemporaine, pour relever les défis actuels. 